\title{
AS INTERFERÊNCIAS FONOLÓGICAS NO INGLÊS COMO LÍNGUA ESTRANGEIRA PARA OS FALANTES DO PORTUGUÊS DO BRASIL
}

\section{Resumo}

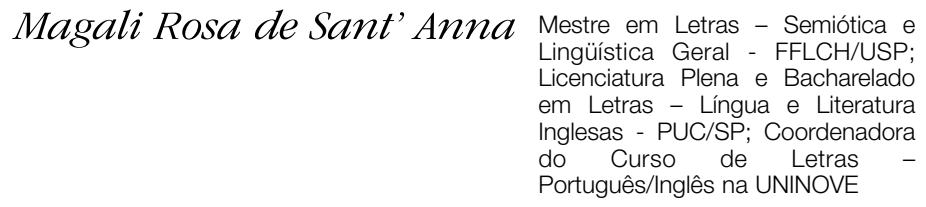

Este texto baseia-se na análise fonológica contrastiva teórica da língua portuguesa como língua materna, e da inglesa, como língua estrangeira, para apresentar os desvios fonológicos que interferem na compreensão da comunicação.

Palavras-chave: lingüística; português; inglês; análise contrastiva; interferências fonológicas.

\section{Abstract:}

This paper is based on the theoretical contrastive phonological analysis of Portuguese as native language and English as target language to present the phonological deviations which interfere in the communication comprehension.

Key words: linguistics; portuguese; english; contrastive analysis; phonological interferences.

\section{Aquisição / aprendizagem do sistema fonológico da LE}

O processo de aprendizagem da língua inglesa como língua estrangeira, ${ }^{1}$ por falantes do português do Brasil (ou não), requer, ${ }^{1 .}$ Língua Estrangeira será grafado para a adequada compreensão das mensagens, a retenção na memória, mediante estudo, observação e experiência na línguaalvo, da gramática, do léxico, da morfologia, da cultura e também da pronúncia correta das palavras. 
De maneira geral, aprender uma LE parece ser um processo complexo e a língua materna ${ }^{2}$ é, provavelmente, uma fonte 2. Língua Materna será grafado imprescindível para a língua-alvo. O que devemos levar em consideração é que a interferência ${ }^{3}$ da LM sobre a língua-alvo é muito freqüente; a LE só será internalizada no momento em que o processo de aprendizagem da língua-alvo for mais abrangente para que ele possa sofrer menos interferências (GLEASON Jr, 1961, p. 364). Ao estudarmos a ocorrência de tal fato, tanto em adultos como em crianças, verificamos certas diferenças: o adulto possui maturação 3. Transferência (também chamada de transferência positiva) seria o uso dos fonemas comuns nas duas línguas a imitação. Quanto à Interferência (ou transferência negativa) seria a tentativa de reprodução de fonemas desconhecidos, ou seja, emprego de um fonema da LM com alguma semelhança ao da LE. Isso, no cognitiva e domínio da LM e utiliza-se de estratégias diferentes daquelas adotadas pela criança na aquisição da primeira língua; por exemplo, o adulto pode apoiar-se no uso da gramática para aprender a LE, ao passo que a criança fará generalizações por inferência.

$\mathrm{Na}$ verdade, a aprendizagem de uma LE não se limita apenas à Fonologia, à Gramática ou à Semântica. O que realmente ocorre é uma forte evidência de que os adultos, ao aprenderem uma outra língua, acessam as mesmas propriedades inatas, como fazem as crianças ao adquirirem a LM. Os métodos de ensino, porém, devem ser outros, pois um adulto não se submeteria a entrar numa sala de aula para ser tratado como um bebê e, além disso, ter de usar a linguagem da criança - a chamada baby-talk, caracterizada pela apresentação de palavras no diminutivo, de vocabulário restrito etc. - para se comunicar. Devemos ressaltar, contudo, que, na medida em que o estudante se torna adulto, a capacidade de aprendizagem de uma língua nova pode ser encarada como um desafio que ele almeja atingir, ou pode ainda ser problemática e difícil, se ele se sentir obrigado a adquiri-la sem nem mesmo gostar dela. Haja vista o inevitável processo de comparação com a LM ou até mesmo com outras LEs que podem interferir no aprendizado.

Assim, podemos dizer que se tornar apto numa LE pode ocorrer em qualquer idade, de diversas maneiras, com diferentes propósitos e nas várias etapas da aprendizagem. Estudiosos, como Harmer (1994, p. 1), por exemplo, apostam em diferentes pontos importantes, principalmente quanto aos propósitos e às motivações que norteiam o estudante durante o processo de aprendizagem da LE.

A estrutura de uma língua consiste tradicionalmente em Fonologia, Gramática e Semântica. Nessa perspectiva, a aprendizagem de uma LE depara com esses 3 termos estruturais 
tradicionais (CRYSTAL, 1987, p. 88). Não se pode deixar de observar que todos esses níveis sejam difíceis de controlar ao mesmo tempo durante a aquisição/aprendizagem da língua-alvo. É evidente, portanto, que, à medida que o aprendiz vai tendo maior contato com a LE, ele vai melhorando seu desempenho comunicacional. Há indícios de que o vocabulário precisa manter-se ativo - já que este varia com facilidade e rapidez -, pois é um traço mutável no domínio de uma língua. Entretanto, dominando uma pequena parcela do vocabulário, o aprendiz pode alcançar resultados razoáveis. É mais freqüente que o domínio das construções sintáticas, traços do sistema de flexão e esquemas de derivação seja mais conhecido e imutável (embora se aproximem do domínio da morfologia) se o compararmos com o do vocabulário. As exigências, porém, são maiores no caso da Fonologia, porque seria um problema absolutamente central, para uma LE, se um fonema ou um grupo de fonemas fossem pronunciados incorretamente pelo aprendiz, pois a comunicação com pessoas nativas poderia ser prejudicada. A linguagem pareceria estranha ao falante nativo e talvez uma barreira social se estabelecesse entre o aprendiz e qualquer um dos membros daquela comunidade, já que a pronúncia deste seria aparentemente 'estrangeira'.

Assim, a Fonologia preocupa-se com a aquisição e a aprendizagem da pronúncia das línguas. Na medida em que comparamos a aquisição da LM por crianças com a aprendizagem da LE por adultos, tendemos a considerar que uma e outra ocorrem em graus diferentes. A necessidade de abordarmos esse problema levanos exatamente à sala de aula, isto é, como o estudante adulto que aprende inglês como LE pronuncia as palavras, frases e sentenças.

Apenas com a análise contrastiva observacional das transferências e interferências é que podemos verificar a previsão e explicação do porquê de um determinado aspecto em que estejamos interessados. Depois do levantamento dos dados observacionais, esse aspecto se revela pedagogicamente importante, porque o estudo da transferência e interferência da LM sobre a LE e demais interferências identificadas e explicadas pela análise de erros pode direcionar o aprendizado para uma diminuição, ou até mesmo a superação das dificuldades com facilidade. Quando conhecemos o problema e sabemos como enfrentá-lo, fica mais fácil vencê-lo. 
Parece-nos relevante mencionar que esses 'erros' servem para mostrar que os alunos estão desenvolvendo o sistema lingüístico da LE e que uma das maneiras de aprender, sob um outro aspecto, é errando, pois, no momento em que o aluno reconhece o erro, ele próprio tenta superá-lo, para alcançar adequadamente um nível de desempenho comunicacional da língua escrita e/ou da falada.

\section{Interferências do sistema fonológico do inglês e do português, em nível teórico}

Sem dúvida, as comparações dos sistemas fonológicos do inglês e do português, realizadas por Mário Mascherpe (1970), Milton M. Azevedo (1981) e Martha Steinberg (1985), igualam-se em vários pontos. Todos esses estudiosos remetem à descrição dos fonemas (consonantais e vocálicos) e seus grupos consonantais, não só os semelhantes, mas também os diferentes existentes nas duas línguas. Dois deles - Mascherpe e Steinberg - apresentam sugestões de como sanar possíveis 'erros' na pronúncia dos estudantes; Steinberg comenta sobre as possíveis interferências da escrita na fala. Dentre os três, apenas Azevedo trata de comparar a entonação.

Mascherpe (1970, p.151-154) apresenta, como conclusão de seu trabalho, alguns pontos que consideramos importante retomar. Ele verificou que há semelhanças e diferenças e que o estudante ouvirá, no início da aprendizagem da Língua Inglesa, apenas os fonemas de sua própria língua, a Língua Portuguesa. ${ }^{4}$ Quando o estudante depara com fonemas semelhantes ou falsamente 4 Língua Inglesa e Língua e LP, respectivamente, no texto. semelhantes, o professor deve ajudá-lo a transferir seus hábitos lingüísticos, com algumas modificações, até que seja capaz de produzir corretamente os fonemas semelhantes da LE; porém, se esses forem absolutamente novos e diferentes, cabe ao professor saber discernir qual técnica deverá ser utilizada para introduzir antes o reconhecimento auditivo desses fonemas e, depois, guiar o aluno para uma reprodução consciente que lhe permita superar as possíveis dificuldades. Com o objetivo de orientar professores e alunos, levando-os a uma comunicação inteligível, o professor apresenta seu próprio material de ensino fonológico para uso em sala de aula e, finalmente, remete seu trabalho aos professores do ensino médio e estudantes dos cursos de Letras, esperando que tal clientela possa fazer bom uso do material. 
A apresentação do trabalho de Azevedo (1981) é um pouco diferente da dos demais trabalhos. Ele revela aspectos muito importantes do contraste de dois sistemas lingüísticos, referindo-se à LP como LE, e à LI, como LM, isto é, seu trabalho é a operação inversa dos outros já mencionados. Ele compara, minuciosamente, fonemas, grupos consonantais, sílaba tônica, palavra tônica na frase ou oração e entonação; trata, assim, tanto dos traços segmentais quanto dos supra-segmentais. No momento em que Azevedo (op.cit., p.69) se refere às semelhanças e às diferenças entre os fonemas de ambas as línguas, menciona que, de acordo com sua coleta de dados, os estudantes falantes da LI (os quais estudavam a LP como LE) não tiveram nenhuma dificuldade ao tentar pronunciar as vogais do português, afirmando que tais estudantes utilizaram sua competência em LI para transferir o sistema vocálico do inglês para a LP. Quanto aos fonemas consonantais surdos do português $/ \mathbf{p} \mathbf{t} \mathrm{k} /$, estes foram articulados com a aspiração necessária para pronunciar tais fonemas ingleses, ocasionando um 'erro' de pronúncia. $\mathrm{Na}$ verdade, podemos supor que, no trabalho de Azevedo, as dificuldades podem estar também nas semelhanças, tal como Mascherpe e Steinberg afirmam em seus trabalhos, não importando aqui qual a LM ou a LE. Os grupos consonantais da LP têm um número limitado de possibilidades (op. cit., p. 86-87), diferentemente da LI que possui um número bastante grande de combinações pertencentes a uma mesma sílaba. Azevedo (op.cit., p. 91-95) acrescenta, mais uma vez, que os grupos consonantais do português não apresentaram dificuldades para o falante da LI. Ele comenta sobre as sílabas tônicas, subtônicas e átonas, exemplificando cada caso e mostrando que há uma variação na posição da sílaba tônica em ambas as línguas. Com relação à entonação, a LI apresenta uma palavra tônica na frase ou na sentença, enquanto a LP tem o hábito de enfatizar quase todas as palavras, o que parece ter ocasionado interferência na aprendizagem dos estudantes da LP falantes da LI (op.cit., p.97-106).

Steinberg (1985, p.17-21), depois de arrolar os fonemas pertencentes à LI e não à LP, destaca que a proximidade articulatória pode ser uma das primeiras dificuldades do aluno quando ele tenta imitar os sons estranhos a sua LM. Isso quer dizer que, ao ouvir, o aluno não percebe que um determinado fonema não pertence ao 
sistema fonológico de sua língua mãe; ao tentar pronunciá-lo, utiliza-se dos fonemas que conhece em sua língua. Como o estudante não reconheceu o fonema 'diferente', ele usará um fonema de sua LM que seja próximo daquele que ele 'pensa' ter percebido e, assim, estará diante do problema causado pela proximidade articulatória. Steinberg exemplifica com o fonema inglês $/ \mathbf{y} /$ (na escrita pode ser $=-\mathbf{n g}=/ \mathbf{y} /$ ou $=-\mathbf{n k}=/ \mathbf{y k} /$ ) que poderá ser pronunciado pelos falantes da LP como /n/. Esta é uma segunda dificuldade, que depende da posição dos fonemas nas palavras, uma vez que cada língua tem um tipo de distribuição dos fonemas nas palavras e, ao compararmos com a nossa língua, alguns podem ocorrer da mesma maneira; outros, não. É o caso dos fonemas $/ \mathbf{p ~ t ~} \mathbf{k ~ b ~ d ~} \mathbf{g ~ f ~} \mathbf{v} \int \mathbf{z} \mathbf{z ~ m}$ / do português que não ocorrem em posição final de palavra, ocasionando o acréscimo de uma vogal de apoio no momento em que o estudante tentar pronunciar tais fonemas: o aluno falará /'kæpı/ 'quépi' em vez de /kæp/ cap. Diferentemente do português, em inglês todos esses fonemas podem realizar-se em posição final de palavras. Um terceiro problema diz respeito às diferentes realizações (=alofones) de um mesmo fonema que podem variar de acordo com suas posições nas palavras. Por exemplo, o fonema inglês /1/ possui alofones com as seguintes distribuições complementares: [1] em posição inicial ou intervocálica, como nas palavras lap [læp] e alone [ə'loun]; [1] diante de consoante ou em posição final de palavra, tal como old [ołd] e call [kho:ł], e [1] quando precedido de /p/, /t/ ou /k/ em sílaba acentuada ou início de palavra: play [pleı]. Quanto à LP, o /1/ realiza-se [w], ou [ow] na sílaba depois de vogal, ou em posição final de palavra. É o caso da palavra portuguesa 'final' que será pronunciada [fi'naw] (exemplo nosso).

\section{Interferências em nível de pronúncia}

Como já afirmamos, a análise contrastiva deve descrever e comparar as semelhanças e diferenças entre duas ou mais línguas e pode ser usada como subsídio para o processo de ensino/aprendizagem, tendo como objetivo principal observar os mecanismos de interferência, entre eles os hábitos de pronúncia dos alunos (perceptivos e articulatórios). Esta passou a ter grande importância para a lingüística aplicada ao ensino de línguas, na 
medida em que suas metas são explicar e decodificar as dificuldades encontradas nas produções dos alunos durante o processo de aprendizagem de uma LE.

Sabemos que habilidades, tais como ler, escrever, falar, ouvir e entender a LM durante o processo de aprendizagem de uma LE, detectadas pela análise contrastiva, interferem no desenvolvimento das mesmas habilidades. Então, adquirir o sistema fonológico da língua-alvo implica não só reconhecer, mas também internalizar, saber reproduzir e controlar os sons dessa língua e suas combinações.

Assim, ao se aprender uma LE, a interferência da LM é absolutamente inevitável. Quanto à pronúncia dos fonemas, podemos também mencionar que a discriminação auditiva tem um papel muito importante para o desenvolvimento fonológico da criança (e para o do adulto também). É a partir da percepção dos fonemas e da tentativa de sua produção que a criança vai adquirindo o sistema fonológico de sua LM. No início da aquisição, ela vive o período do balbucio, emitindo sons e também tentando reproduzir os sons que ouve, o que nem sempre consegue; algumas vezes, a criança, por um curto espaço de tempo, utiliza-se somente das sílabas tônicas das palavras para comunicar-se. Isto quer dizer que a criança simplifica ao máximo a língua que escuta antes de tentar reproduzi-la. Durante o crescimento, ela transpõe vários períodos de aquisição fonológica e, ao começar tal desenvolvimento, constata-se uma aproximação entre sua fala e a do adulto. Entretanto, devemos considerar que a rapidez na aquisição da LM deve-se ao fato de ser esta a primeira língua com que a criança tem contato, portanto, mais fácil imitar. Ao abordar a aprendizagem fonológica de uma LE, notamos que essa pode ser uma tarefa mais árdua para o adulto, pois, embora ele já saiba comunicar-se em sua língua, a interferência do sistema fonológico desta será um fator importantíssimo para o desenvolvimento da aprendizagem. Tal interferência deve ser considerada para fins pedagógicos, para que sejam superados os problemas de transferência negativa. Assim, a interferência fonológica ocorre quando se transfere sons da LM para a LE, por julgar-se que os fonemas da língua-alvo são semelhantes aos da nossa língua. Contudo, no contraste dos dois sistemas sonoros, todas as dificuldades de pronúncia podem ser apontadas, 
prevendo os possíveis 'erros', os quais podem ser sanados com exercícios específicos.

Entre os traços de interferência da LM causadores de desvios fonológicos, podemos citar as especificidades fonológicas (particularidades fonológicas) da língua-alvo, a alofonia diferente e a proximidade fonética.

Tomemos como parâmetro os falantes da LP que estudam a LI como LE e poderemos presumir algumas dificuldades fonológicas em nível segmental durante o aprendizado da línguaalvo, ${ }^{5}$ que serão desenvolvidas a seguir, de acordo com o tipo de interferência mencionado.

As particularidades fonológicas são aquelas que fazem parte 5 Embora estejamos abordando artigo tratará apenas dos problemas de pronúncia no que se refere aos fonemas consonantais. Não podemos, porém, deixar de mencionar a importância dos do sistema articulatório daquela língua especificamente, quando aspectos supra-segmentais. comparada com uma outra. Tais aspectos podem ser mais bem esclarecidos com os seguintes exemplos:

a) no caso de os fonemas nasais bilabial e alveolar ingleses não possuírem um fonema consonantal correspondente a cada um deles na LP. Por isso, as sílabas com a terminação em $m$ ('sempre'), e em - $n$ ('nunca'), e as palavras do português terminadas em -m ('vem') são pronunciadas como vogais nasais / $\widetilde{a}$ e $\tilde{\mathbf{1}} \tilde{\mathrm{o}} \tilde{\mathrm{u}} /$. Conseqüentemente, quando o aluno de LI tenta pronunciar as palavras inglesas com $-m,-m e,-n,-n e$ finais, num primeiro momento, ele o fará como vogais nasais, acrescentando, depois, uma vogal epentética ou de apoio;

b) os 12 fonemas vocálicos da LI /i: I e æ $\mathbf{\Lambda}$ 3: o a: $\mathbf{D}$ o: $\mathbf{U}$ u:/ que não fazem parte do inventário de fonemas da LP, a qual contém 7 vogais orais /a $\varepsilon$ e $\mathbf{i}$ o o v/ e 5 nasais / ̃a e $\tilde{1} \tilde{\mathrm{o}} \tilde{\mathrm{u}} /$. Em princípio, trariam dificuldades para $\mathrm{o}$ estudante, principalmente porque o inglês acusa ainda vogais longas e breves. Todas as vogais longas podem passar despercebidas pelo estudante, que tentará imitar os sons que ouve; entretanto, ao fazê-lo, não percebe o traço distintivo (longas e breves), pronunciando-as todas curtas;

c) os fonemas $/ \mathbf{p ~ t ~} \mathbf{k} \mathbf{b} \mathbf{d} \mathbf{g} \mathbf{f} \mathbf{v} \mathbf{z} \mathbf{\int} \mathbf{3} /$ podem ocorrer no final de sílabas na LI; ocorrem na LP, mas não em final de sílabas. Tais fonemas provavelmente serão pronunciados com o acréscimo de uma vogal epentética, pelo falante da 
LP, durante a aprendizagem da LI, o que resultará ainda num acréscimo do número de sílabas à palavra. Tal especificidade pode ser um aspecto difícil de o estudante de LI superar;

d) na LI, os substantivos no plural, a $3^{\text {a }}$ pessoa do singular dos verbos no tempo presente e o caso genitivo têm três possibilidades de finalização das palavras, conforme o fonema que finaliza a palavra antes de se acrescentar o sufixo. São elas: /-s/, para as palavras com terminação /p

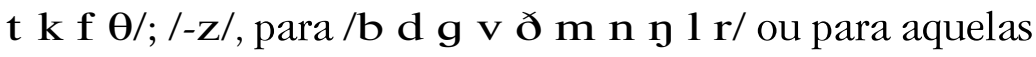
que terminem em fonema vocálico, e /-Iz/, para /s z $\int \mathbf{3}$ t c 3 /. Essas terminações também podem ser difíceis para o estudante;

e) os verbos regulares da LI - aqueles com terminação em - ed - apresentam três possibilidades de pronúncia, de acordo com o fonema anterior ao acréscimo do -(e)d:/-t/, para os verbos terminados em /p k f $\boldsymbol{\theta} \mathbf{s} \int \mathfrak{t} / ; / /-d /$, para aqueles

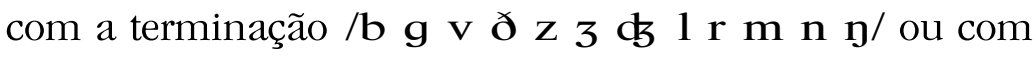
fonema vocálico, e/-Id/, para verbos com a finalização em /t d/. A adição de tais sufixos também pode trazer dificuldades para o estudante;

f) na LI, existem grupos consonantais em início de palavra, tais como /sp-/, /st-/, /sk-/, /sl-/, /sm-/ e /sn-/ que, por não ocorrerem da mesma forma no português, podem levar os estudantes a acrescentar, antes dos tais grupos, uma vogal de apoio. O fato é que qualquer grupo consonantal do inglês, em início ou final de palavra, pode trazer dificuldades de pronúncia para o estudante de LI. É preciso ressaltar que, principalmente o grupo consonantal final, por representar um número bastante extenso de possibilidades, se comparado ao da LP (com um número bem menor de possibilidades), pode trazer aos estudantes problemas de pronúncia. Isso ocorre porque tais características são específicas da LI, ou seja, há uma diversidade de grupos consonantais ingleses bem maior que os existentes na LP.

A alofonia diferente entre as duas línguas pode levar o estudante a pronunciar as diferentes realizações de alguns fonemas 
ingleses da maneira como está habituado a fazê-lo em sua própria língua, e talvez esse seja o problema mais difícil de superar durante o processo de aprendizagem da LI. Vejamos os casos a seguir:

a) devemos ressaltar aqui que, na LI, os fonemas africados $/ \mathbf{t} \mathbf{d} /$ podem trazer problemas para o estudante que não utilizá-los em sua própria língua. No caso da LP, tais fonemas são alofones dos fonemas $/ \mathbf{t} \mathrm{d} /$ respectivamente, apenas em algumas regiões do Brasil;

b) o fonema lateral inglês /1/ possui os alofones [1] no início de sílaba ou posição intervocálica, [ł] no final da sílaba ou diante de um fonema consonantal e [1] se for precedido de /p/, /t/ ou /k/ no começo da palavra ou na sílaba tônica. Como a LP só possui a realização [1], é possível que o estudante encontre dificuldade ao pronunciar tais alofones, vocalizando a consoante, isto é, o fonema lateral pode ser pronunciado com o ditongo /ow/ ou /w/, depois de uma vogal;

c) os fonemas oclusivos surdos do inglês $/ \mathbf{p} \mathbf{t} \mathrm{k} /$, em início de sílaba ou na sílaba tônica, possuem uma aspiração, tendo como alofone o $\left[\mathbf{p}^{\mathbf{h}}\right]$, o $\left[\mathbf{t}^{\mathbf{h}}\right]$ e o $\left[\mathbf{k}^{\mathbf{h}}\right]$, respectivamente. Tal particularidade no nível de realização de um fonema pode levar o estudante a uma pronúncia diferente, pois a LP não possui essa forma de realização para os fonemas surdos oclusivos. O português contém os seguintes alofones: [p], para o /p/; [t] e [t] ], para o/t/, e [k], para o /k/.

A proximidade fonética, como a própria palavra diz, é um fonema da LM que possui uma articulação muito próxima ao fonema da LE que não se realiza na língua mãe. Podemos exemplificar com:

a) os fonemas interdentais ingleses / $\boldsymbol{\theta}$ ð/ (que não fazem parte do sistema articulatório da LP), que, possivelmente, serão substituídos por $/ \mathbf{t} \mathbf{f} \mathbf{s} /$, para o fonema surdo $/ \boldsymbol{\theta} /$, e por $/ \mathbf{d}$ $\mathbf{v ~ z / , ~ p a r a ~ o ~ f o n e m a ~ s o n o r o ~ / ð / ; ~}$

b) os fonemas africados $/ \mathbf{t} \int \mathbf{b} /$ que podem ser substituídos por / 3 /, se o estudante não tiver o hábito de utilizar as africadas na LP, como realizações dos fonemas oclusivos / $\mathbf{t}$ $\mathrm{d} /$, respectivamente; 
c) a fricativa glotal inglesa $/ \mathbf{h} /$ pode ser substituída pelo falante da LP, tanto pelo fonema líquido (vibrante múltipla) / $\mathrm{x} /$ quanto por nenhum fonema. Embora ambas as línguas envolvidas possuam palavras iniciadas pela letra h-(tal fato pode levar o aluno a não utilizar nenhum fonema porque, na LP, esta letra não tem pronúncia, ou seja, o falante do português sabe que não existe fonema correspondente a tal letra), que podem ser mudas. A LI possui também outras palavras em que a fricativa glotal deve ser pronunciada, por isso a substituição pelo fonema líquido do português;

d) a nasal velar inglesa /y/ provavelmente seja substituída por /n/ pelos estudantes, devido à inexistência deste fonema na LP.

\section{Sobre outros motivos causadores de desvios possíveis de explicar}

Um tipo de interferência bastante óbvio parece ser a escrita. Tanto o inglês quanto o português utilizam o alfabeto latino e, à primeira vista, parece fácil a leitura das palavras em ambas as línguas. Porém, durante o processo de aprendizagem da LI, os estudantes sentem muita dificuldade ao pronunciá-las, porque na LP os fonemas que representam as letras, em sua grande maioria, são os mesmos, e isso não ocorre com a língua-alvo (muito embora a forma escrita nem sempre seja a ilustração de um fonema). Quanto aos fonemas ingleses, eles não possuem uma correspondência regular entre o som e a letra, ou seja, um mesmo fonema pode ser representado por várias letras. É o caso do fonema $/ \mathrm{m} /$, que na LI pode ser representado pelos grafemas $m, m m, m e, m n, m b, g m$ e Im, nas palavras moon /mu:n/, common /'ka:mon/, same /seIm/, solemn /'sa:lom/, climb /klaim/,phlegm /flem/ e calm /ka:m ka:lm/, respectivamente 'lua', 'comum', 'mesmo', 'solene', 'subir', 'mucosidade' e 'calmo', enquanto na LP tal letra é representada somente pelo fonema $/ \mathrm{m} /$, como na palavra 'mala' em que o grafema é idêntico ao fonema - (Steinberg, 1985, p. 64). Podemos refletir também sobre a possibilidade de o estudante utilizar o fonema / $/ \mathrm{t}$ para ambos os fonemas interdentais ingleses $/ \boldsymbol{\theta} \mathrm{d} /$ : uma vez que estes fonemas não existem na LP, parece ser uma mera transferência da leitura para a pronúncia, isto é, em português a letra $h$, como já dissemos, não possui nenhum valor fonético - como na 
palavra 'homem'-, exceto quando acompanhada das letras $n$ ou $l$, levando à produção de outros dois fonemas - /ñ $/$, para as letras $n h$ e $/ K /$, para as letras $l h$. Então, se a letra $h$ se agrupa à letra $t$, formando th, para os falantes da LP seria fácil e comum articular qualquer palavra com essa grafia utilizando apenas o som do $t$ do português. Para ilustrar esse aspecto, citamos, para o fonema surdo inglês, a palavra thanks / $\theta æ \mathbf{k s} /$, que pode ser pronunciada /tæyks/; para o sonoro, a palavra leather/leðor/, que pode ser pronunciada /ledər/ pelos falantes do português. Assim, podemos afirmar que as dificuldades de leitura das palavras inglesas surgem também da confusão que se faz entre grafia e pronúncia.

Há outros aspectos que podem ser notados quando o falante se expressa em sua própria língua, como os lingüísticos (quando ele expressa a sua linguagem) e os extralingüísticos (nas informações diferentes sobre o falante) (Gleason Jr., 1961, p.8). São os fatores extralingüísticos que informam a respeito do falante - por exemplo, se esse falante pertence às nossas relações, se o seu discurso é formal ou informal, se ele é do sexo feminino ou masculino, se é criança ou adulto, qual é seu nível de escolaridade e, até mesmo, qual é o nível socioeconômico a que ele pertence. Todos esses fatores são externos à língua, que, por meio da linguagem desses falantes, podemos identificar e considerar para uma possível análise.

Se levarmos em conta que essa análise pode ser um estudo da língua em relação à sociedade, estaremos entrando no campo da sociolingüística, que trata da descrição da língua confrontada com os fatores sociais. Uma vez que um falante não utiliza identicamente os mesmos termos que o outro, com uma pronúncia perfeitamente igual, é muito importante que pesquisadores como W. Labov (1972), A R. Hudson (1980), F. Tarallo (1986) e M. C. Mollica (1992), por exemplo, tenham-se preocupado com tal aspecto, isto é, com o desenvolvimento da língua relacionada ao desenvolvimento da sociedade. No caso da experiência fonológica de um falante, podemos afirmar que ela é sempre diferente da pronúncia da dos outros falantes.

Os sociolingüistas preocupam-se com as variáveis lingüísticas e sociais e apresentam resultados, provando que cada falante é único e sua prática sociolingüística o porá dentro de um modelo em que as situações podem ser semelhantes. No entanto, 
diante de uma fala que é um ato de identidade (Hudson, 1980, p.14), cada falante absorverá as informações que lhe interessarem. Por outro lado, sua idade, sexo, nível socioeconômico e escolaridade fazem parte de um contexto social e podem ser considerados fatores que influenciam a fala individual, dando uma visão clara de quem é esse falante.

A sociolingüística afirma, então, que cada falante é único, pois ele é provido não somente de experiências lingüísticas, mas também extralingüísticas, o que nos auxilia a realizar essa análise. Deve-se notar ainda que isso ocorre desde o início da aquisição da língua pela criança. De maneira geral, os bebês têm como modelo de linguagem seus pais e tentam imitar as atitudes e os sons que ouvem; à medida que vão atingindo a pré-adolescência, passam a notar e usar o mesmo código lingüístico de seus pares e, do final da adolescência em diante, passam a observar e utilizar a fala de outros adultos. É por esse caminho que o falante procura sua identidade, tornando-se único.

Em suma, podemos afirmar que língua alguma pode ser dissociada de seu contexto social; por isso, a sociolingüística analisa qual é o contexto que caracteriza o falante, ou seja, como o desenvolvimento da sua fala relaciona-se ao significado de seu comportamento social enfocando, algumas vezes, as diferentes pronúncias que os falantes venham a ter.

\section{Referências}

AZEVEDO, M. M. A. Contrastive Phonology of Portuguese and English. (Tese de Doutoramento). Whashington, DC: Georgetown University Press, 1981.

CRYSTAL, D. The Cambridge Encyclopedia of Language. New York, Cambridge: Cambridge University Press, 1987.

GLEASON Jr., H. A. Introdução à lingüística aplicada. 2. ed. Trad. João Pinguelo. Lisboa: Fundação Calouste Gulbenkian, 1961.

HARMER, J. The Practice of English Language Teaching. (New Edition) New York: Longman Handbooks for Language Teachers, 1994.

HUDSON, R. A. Sociolinguistics. Cambridge: Cambridge University Press, 1980. 
JONES, D. English Pronunciation Dictionary. New York: Cambridge University Press, 1997.

KLEIN, W. Second Language Acquisition. New York: Cambridge University Press, 1986.

LABOV, W. Sociolinguistic Patterns. Philadelphia: University of Pennsylvania Press, 1972.

MASCHERPE, M. Análise comparativa dos sistemas fonológicos do Inglês e do Português. (Tese de Doutoramento.) Assis: Faculdade de Filosofia, Ciências e Letras de Assis, 1970.

MOLLICA, M. C. (Org.). Introdução à sociolingüústica variacionista. Rio de Janeiro: CEG/UFRJ, 1992. (Cadernos didáticos).

ODLIN, T. Language Transfer. New York: Cambridge University Press, 1989.

SCHUMACHER, C.; White, P. de L.; Zanettini, M. Guia de pronúncia do inglês para brasileiros: soluções práticas para falar com clareza. Rio de Janeiro: Campus, 2002.

SILVA, T. C. Fonética e fonologia do português: roteiro de estudos e guia de exercícios. 6. ed. São Paulo: Contexto, 2002.

SILVEIRA, R. C. P. Estudos de fonologia portuguesa. São Paulo: Cortez, 1986.

Cortez, 1988.

. Estudos de fonética do idioma português. São Paulo:

STEINBERG, M. Pronúncia do inglês norte-americano. São Paulo: Ática, 1985.

TARAllo, F. A Pesquisa sociolingüística. 2. ed. São Paulo: Ática, 1986. 